\title{
Introduction to the Nuclear
Engineering book series
}

INSTN, the National Institute for Nuclear Science and Technology, is a higher education institution founded in 1956 as part of French Alternative Energies and Atomic Energy Commission (CEA). INSTN is specialized in nuclear education and training, and contributes to the human resources development required by nuclear research and industry, from operators to engineers, and researchers. INSTN's main objective is to contribute to disseminating CEA's expertise through specialized courses and continuing training, not only on a national scale, but across Europe and worldwide.

Bolstered by the CEA's efforts to build partnerships with universities and engineering schools, the INSTN has developed links with other higher education institutions, leading to the organisation of more than thirty jointly-sponsored Masters graduate diplomas. There are also courses covering disciplines in the health sector: nuclear medicine, radio-pharmacy and also a specific degree for hospital physicists.

Continuous education is another important sector of INSTN's activities that relies on the expertise developed within the CEA and by its industry partners.

INSTN's "Génie Atomique" known as "GA" course is a specialised course in nuclear engineering that can be considered as a master after the master course. The course was first taught in 1954 at the CEA Saclay research centre, where the first experimental piles were built, and since 1978 it has also been taught in CEA Cadarache research centre, where the fast neutron research reactors were developed. Starting from 1958, the "GA" course is taught at the School for the Military Applications of Atomic Energy (EAMEA), under the responsibility of the INSTN. Since its creation, the INSTN has graduated over 5000 engineers who did work in major companies or public-sector bodies in the French nuclear industry: CEA, EDF, AREVA, Marine Nationale (the French navy), IRSN (French TSO)... Many foreign students from a variety of countries have also studied for this diploma.

There are two categories of student: civilian and military. Civilian students will obtain jobs in the design, the construction or the operation of nuclear power plants or research establishments as well as in the fuel processing facilities. They can aim to become expert consultants, analysing nuclear risks or assessing environmental impact. The EAMEA provides education for officers assigned to French nuclear submarines or the aircraft carrier.

The teaching faculty comprises CEA research scientists, experts from the Nuclear Safety and Radiation Protection Institute (IRSN), and engineers working in industry (EDF, AREVA, etc.). The main subjects are: nuclear and neutron physics, thermal hydraulics, nuclear materials, mechanics, radiological protection, nuclear instrumentation, operation and safety of Pressurized Water Reactors (PWR), nuclear reactor systems, and the nuclear fuel cycle. These courses are taught over a seven-month period, followed by a final project that rounds out the student's training by applying it to an actual industrial situation. These projects take place in the CEA's research centres, companies in the nuclear industry (EDF, AREVA, etc.), and even abroad (USA, Japan, Canada, United Kingdom, etc.). A key feature of this programme is the emphasis on practical work carried out using the INSTN facilities (ISIS training reactor, PWR simulators, radiochemistry laboratories, etc.). 
Even now that the nuclear industry has reached full maturity, the "Génie Atomique" diploma is still unique in the French educational system, and affirms its mission: to train engineers who will have an in-depth, global vision of the science and the techniques applied in each phase of the life of nuclear installations from their design and construction to their operation and finally, their dismantling.

The INSTN has committed itself to publishing all the course materials in a series of books that will become valuable tools for students, and to publicise the contents of its courses in French and other European higher education institutions. These books are published by EDP Sciences, an expert in the promotion of scientific knowledge, and are also intended to be useful beyond the academic context as essential references for engineers and technicians in the nuclear industrial sector.

Joseph Safieh

"Génie Atomique" Course Director 2000-2014 